\title{
Image findings of filler-related radiopacities and multiple miliary osteoma in facial region
}

\author{
Young-Eun Kwon ${ }^{1}$ and Seo-Young $\mathrm{An}^{2 \star}$ \\ ${ }^{1}$ Doctor of Dental Clinic, 7 Promise Dental Clinic, Daegu, Republic of Korea \\ ${ }^{2}$ Associate Professor, Department of Oral and Maxillofacial Radiology, School of Dentistry, IHBR, Kyungpook National University, Daegu, Republic of Korea
}

The identification of radiopacities in the facial region is important during routine radiographic examination. This study analyzed the radiographic findings of filler-related radiopacities (FRR) and multiple miliary osteomas (MMO) in this region using dental radiographs. Image data were obtained from patients at the Kyungpook National University Dental Hospital. Cone-beam computed tomography $(\mathrm{CBCT}) / \mathrm{CT}$ data of patients with multiple facial radiopacities on plain images (panoramic and periapical images; 16 FRR and $224 \mathrm{MMO}$ ) were collected and matched with the corresponding conventional images. In the CBCT/CT images, the FRRs were mainly observed in the cheek (87.5\%) and retromaxillary space (68.8\%) whereas the MMOs were mostly located in the superficial areas of the cheek $(81.3 \%)$ and chin $(36.2 \%)$. The statistical differences were only in the retromaxillary space $(p<0.05)$. The FRRs were mostly ring-shaped (68.8\%) or nodular in appearance (56.3\%), whereas the MMOs presented as calcific foci (96.4\%). The results of the chi-square test revealed statistically significant differences in the detection of FRRs and MMOs in the panoramic images $(p<0.05)$, but not the periapical images. The FRRs were located in the deeper layers of the skin and were more diverse in appearance than the MMOs. Moreover, FRRs were better identified than MMO in the panoramic images. Dentists should have knowledges about image findings of FRRs and be able to differentiate them from MMOs based on the radiographic images.

Key Words: Cone-beam computed tomogrphy; Dermal filler; Radiography, dental

(c) This is an open-access article distributed under the terms of the Creative Commons Attribution Non-Commercial License (http://creativecommons.org/licenses/by-nc/4.0) which permits unrestricted noncommercial use, distribution, and reproduction in any medium, provided the original work is properly cited.

\section{Introduction}

Fillers are recognized as soft tissue augmentation materials [1], such as improving wrinkled skin and correcting contour of 'Human immunodeficiency virus (HIV)-associated facial lipoatrophy [2]. Administering facial cosmetic filler into a deep dermal site can result in a youthful appearance in a noninvasive manner [3]. Since the 1980s when bovine collagen was introduced to improve wrinkles [2], various types of temporary or permanent dermal fillers have been developed [4]. These fillers can be observed as radiopacities on not only in panoramic and intraoral radiographs $[1,5,6]$ but also in cone-beam computed tomography (CBCT) [7], computed tomography (CT) and magnetic resonance imaging (MRI) [3]. Moreover, they may mask normal anatomical structures or make radiographic diagnosis difficult without accurate history or clinical information $[1,5,6]$. Accoring to case reports, filler itself or foreign body formation from the

Received May 28, 2021; Revised August 13, 2021; Accepted August 17, 2021

*Corresponding author: Seo-Young An, Department of Oral and Maxillofacial Radiology, IHBR, Kyungpook National University, School of Dentistry, 2177 Dalgubeol-daero, Jung-gu, Daegu 41940, Republic of Korea.

Tel: +82-53-600-7423, Fax: +82-53-425-6025, E-mail: syan@knu.ac.kr

Copyright (๑) 2021, Oral Biology Research Institute 
filler can be seen as cluster of multiple radiopaque shadows in the buccal cheek area on the conventional radiograph [5,6] and CBCT [7].

Multiple miliary osteoma (MMO) is known as a nodular skin lesion characterized by a tiny cutaneous ossification in the dermis or epidermis of facial skin area [8-10]. It is also observed on the extraoral radiograph [11] and CBCT [12] as multiple small radiopacities ranged from $1.5 \mathrm{~mm}$ nodules to almost indistinguishable [11] and it should be distinguished from the radiopacities of filler [7].

Whereas some small radiopacities may be detected on two-dimensional (2D) conventional radiographs, due to the close proximity of soft tissue structures, other fine calcifications can be missed by the overlapping of complex bone structures. Nowadays, the use of three-dimensional (3D) images such as CT, CBCT have been increasing in order to improve the accuracy of diagnosis in dentistry. They make it possible to identify intriguing radiopacities of the facial area (e.g., FRR, MMO) exactly that can be overlooked in routine examination $[13,14]$.

This study aims to analyze and compare the radiographic features of FRR and MMO in terms of the location and shape using 3D (CBCT/CT) and 2D (panoramic and periapical radiograph) images observed in routine dental practice.

\section{Materials and Methods}

\section{Data collection}

Two approaches of subject collection were used to gain images of FRR and MMO with both 3D CBCT/CT and 2D panoramic images through PACS viewer (INFINITT PACS Version 3.0.11.3 BN104; Infinitt Healthcare, Seoul, Korea) under the hypothesis that detection rate may be different between 2D and 3D images. First, we used a database of Kyungpook National University Dental Hospital from January 2004 to December 2015 to obtain panoramic images that transcribed as "multiple facial radiopacities" or "multiple miliary ostoma”. FRR could not be included into search condition because it had not been considered as description on the plain image before this study. Then only those with $\mathrm{CBCT}$ or $\mathrm{CT}$ were chosen manually among the result of the first search. Conversely, on the second approach, we reviewed CBCT/CT images which were taken in 2015 (from January to December) to find the patients with multiple calcifications related with MMO or FRR on the facial area. Then, only those with panoramic images were included among the result. In the case of the periapical images, we included them covering FRR or MMO sites manually observed in the 3D images. This study was approved by institutional review board (IRB No. 2017-0093).

3D images were acquired with CT (Lightspeed Ultra; GE Healthcare, Milwaukee, WI, USA) using 200-500 mm $\times$ 200-500 mm field of view at $120 \mathrm{kVp}$ and 35-40 mA (Slicing thickness 1.25-2.5 mm) and CBCT (Pax-Flex 3D; Vatech, Seoul, Korea) using a $120 \mathrm{~mm} \times 85 \mathrm{~mm}$ or $50 \mathrm{~mm} \times 50 \mathrm{~mm}$ field of view at $90 \mathrm{kVp}$ and $10 \mathrm{~mA}$ (Slicing thickness 0.4 $\mathrm{mm}) .2 \mathrm{D}$ Conventional images were obtained with panoramic (Orthopantomograph OP 100 and Orthopantomograph OP 100D; Instrumentarium Imaging, Tuusula, Finland) and periapical (Kodak RVG 6100; Carestream Health, Inc., Rochester, NY, USA) radiograph.

\section{Image evaluation}

We evaluated CBCT/CT images that showed the maxillofacial area well and excluded the images with narrow (1/6 arch or less) field of view or severe artifact. When a patient had image modalities, we chose the image with the best quality. MMO was regarded when multiple small calcifications were present on the skin surface without any other abnormal findings of surrounding tissues on CBCT/ CT image $[10,12,15]$. FRR was regarded when multiple calcifications were present in the deep part of the skin without other abnormal findings of surrounding tissue and filler history was confirmed by medical record or telephone interview.

The radiographic features were analyzed according to the location and shape. Location was classified as forehead, temple, retromaxillary area, cheek, nose, nasolabial fold, chin and neck based on the CBCT/CT image. Shapes were classified as foci, nodule, plate-like, ring, and shadow on CBCT/CT and plain images, respectively. Criteria for shape classification were: "foci" for granular radiopacities less than $2 \mathrm{~mm}$, "nodule" for 2-5 mm rounded particle, "plate-like" or 
"multiple plaque" for more than $5 \mathrm{~mm}$ linear stranded with continuous aggregation of nodule and foci, "ring" for having an internal radiolucent area with external radiopaque rim, and "shadow" for amorphous and generally blurred appearance. Detection rate of MMO and FRR was considered in plain radiography. Two examiners, a faculty member certified as a specialist in oral and maxillofacial radiology with 11 years experiences and a third year of resident with reading more than 7000 dental images per year in the oral and maxillofacial radiology, assessed the images with a 21.2 Inch WIDE CX30p 3MP Color LED Diagnostic Monitor (WIDE Corporarion, Hwaseong, Korea). The images that examiners disagreed with each other came to a consensus with two people looking back together and uncertain images were excluded.

\section{Statistical analysis}

The results were evaluated by descriptive statistics. Pearson's chi-square test of fisher's exact test was used to confirm the significance of differences in location, shape, and detection rate between FRR and MMO groups (SPSS Statistics for Windows, version 22.0; IBM Corp., Armonk, NY, USA). A $p$-value $<0.05$ was considered significant.

\section{Results}

Total of $224 \mathrm{MMO}$ and 16 FRR cases were collected. The sex and age distributions of the two entities were compared using a double bar graph (Fig. 1) The $224 \mathrm{MMO}$ subjects broadly ranged in age from 11 years to 91 years with a mean of 54 years. Sex distribution was 130 (58.6\%) for males and 94 (42.3\%) for females. The FRR group, which consisted of 16 people, ranged in age from 44 to 88 years, with an average of 71.1 years and the number of women (13 of $16,81.3 \%$ ) was significantly higher than that of men (3 of

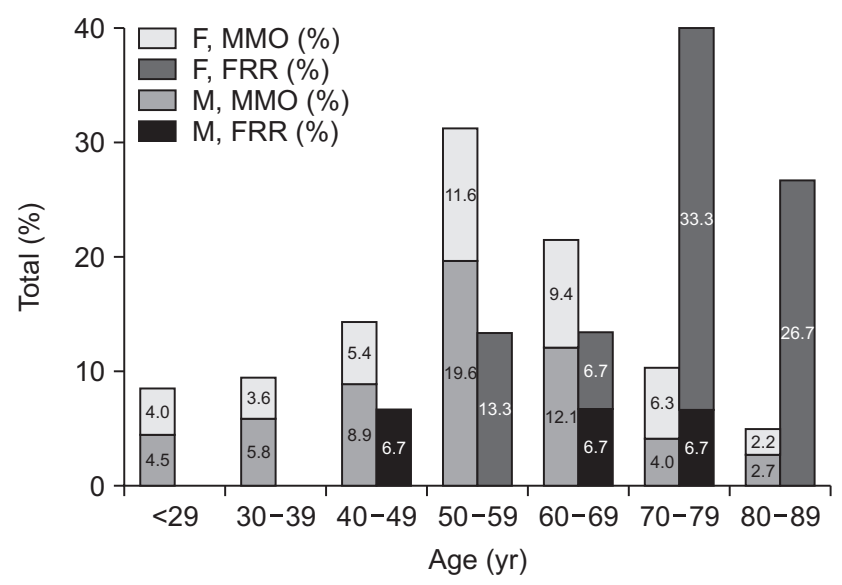

Fig. 1. Age and sex distribution. FRR, filler-related radiopacity; MMO, multiple miliary osteoma; F, female; $\mathrm{M}$, male.

Table 1. List of FRR cases

\begin{tabular}{|c|c|c|c|c|c|}
\hline Case no. & Sex & Age & Time of procedure & Filler site & Type of Procedure \\
\hline 1 & $\mathrm{~F}$ & 59 & 40 years ago & Both cheek & Unlicensed \\
\hline 2 & $\mathrm{~F}$ & 59 & 20 years ago & Both cheek & Unlicensed \\
\hline 3 & $\mathrm{~F}$ & 65 & - & - & Unlicensed \\
\hline 4 & $\mathrm{~F}$ & 69 & 50 years ago & Nose & Licensed \\
\hline 5 & $\mathrm{~F}$ & 70 & 35 years ago & Forehead, both cheek & Unlicensed \\
\hline 6 & $\mathrm{~F}$ & 71 & 40 years ago & Nasolabial fold & Unlicensed \\
\hline 7 & $\mathrm{~F}$ & 74 & Decades ago & Both cheek & Unlicensed \\
\hline 8 & $\mathrm{~F}$ & 75 & 50 years ago & Chin (marionette lines) & Unlicensed \\
\hline 9 & $\mathrm{~F}$ & 75 & 50 years ago & Both cheek & Unlicensed \\
\hline 10 & $\mathrm{~F}$ & 83 & 40 years ago & - & Unlicensed \\
\hline 11 & $\mathrm{~F}$ & 84 & - & - & Unlicensed \\
\hline 12 & $\mathrm{~F}$ & 87 & - & - & Unlicensed \\
\hline 13 & $\mathrm{~F}$ & 88 & 20 years ago & Both cheek, nasolabial fold & Unlicensed \\
\hline 14 & M & 44 & 1 year ago & Nasolabial fold & Licensed \\
\hline 15 & M & 63 & 40 years ago & Temporal area & Unlicensed \\
\hline 16 & M & 71 & 40 years ago & Both cheek & Licensed \\
\hline
\end{tabular}

FRR, filler-related radiopacity. 


\section{$16,18.8 \%)$.}

Table 1 summarized the list of FRR cases with conventional radiograph and $\mathrm{CBCT/CT}$ images together in this study. The most common filler sites were both cheeks in 7 cases, followed by the nasolabial fold in 3 cases, the remaining temporal, forehead, marionette lines, and nose in one case respectively. Most of them (11 of 16) were injected cosmetic filler 20 years ago, with the exception of one case (1 year ago). Moreover, most rejuvenation procedures (13 of 16) were performed by unlicensed persons. Fig. 2 and Table 2 analyzed the 3D locations of FRR and MMO observed in CBCT/CT as gold standard. FRR was found in subcutaneous or dermis tissues symmetrically with higher attenuation material than surrounding fat and soft tissue. The majority of FRRs were located in cheek (87.5\%) and retromaxillary space (68.8\%). MMOs exist bilaterally in the superficial area of skin, and are most commonly found in cheek (81.3\%) and chin (36.2\%). We also found that the multiple radiopacities of the retromaxillary space had significantly higher prevalence in the FRR compared to MMO $(p<0.05)$ (Table 2$)$.

Table 3 compared shapes of FRR and MMO on CBCT/ $\mathrm{CT}$, panoramic and periapical images. FRR was observed in various shapes such as nodule, ring, plate-like, and shadow in decreasing in order on both CT and plain images. However, shape of MMO was mainly detected in foci form on $\mathrm{CT}$ and periapical radiographs. In $\mathrm{CBCT} / \mathrm{CT}$, FRR was sig-
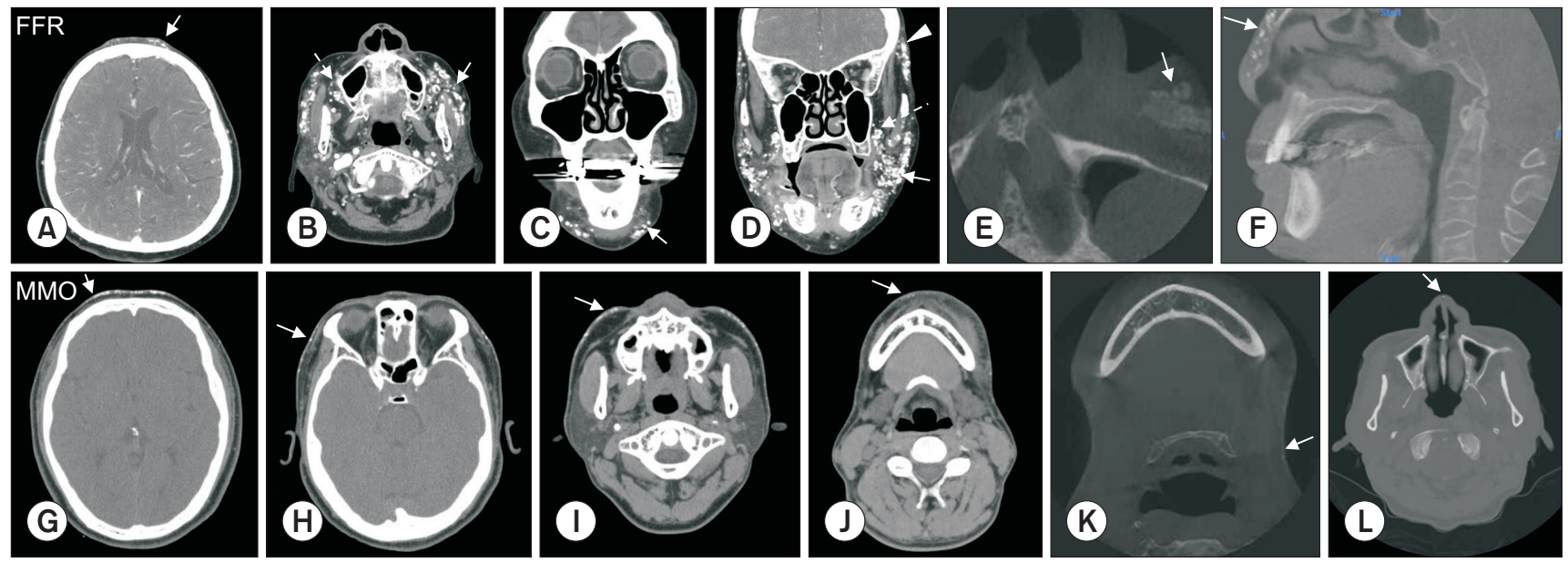

Fig. 2. Location of FRR and MMO. FRR with numerous in subcutaneous tissue of forehead (A, arrow), cheek (B and D, arrow), chin (C, arrow), temple ( $\mathrm{D}$, arrow head), and retromaxillary space (B and D, dotted arrow) in contrast-enhanced CT images and nasolabial fold (E, arrow) and nose (F, arrow) in CBCT images. MMO with superficial layer of forehead (G, arrow), temple (H, arrow), cheek (I, arrow) and chin (J, arrow) in contrast-enhanced CT images and neck (K, arrow) and nose (L, arrow) in CBCT images. FRR, filler-related radiopacity; MMO, multiple miliary osteoma; CBCT, cone-beam computed tomography; CT, computed tomography.

Table 2. Location of FRR and MMO on CBCT/CT images

\begin{tabular}{lccc}
\hline \multicolumn{1}{c}{ Location } & FRR (n=16) & MMO (n=224) & p-value \\
\hline Cheek & $14(87.5)$ & $181(80.8)$ & 0.743 \\
Retromaxillary space & $11(68.8)$ & - & $0.000^{*}$ \\
Chin & $3(18.8)$ & $81(36.2)$ & 0.186 \\
Temple & $3(18.8)$ & $12(5.4)$ & 0.068 \\
Forehead & $1(6.3)$ & $35(15.6)$ & 0.478 \\
Nasolabial fold & $1(6.3)$ & - & 0.067 \\
Neck & - & $8(3.6)$ & 1.000 \\
Nose & $1(6.3)$ & $3(1.3)$ & 0.243 \\
\hline
\end{tabular}

Values are presented as number (\%).

FRR, filler-related radiopacity; MMO, multiple miliary osteoma; CBCT, cone-beam computed tomography; CT, computed tomography.

${ }^{\star}$ Significant difference. 
Table 3. Shape of FRR and MMO classified by image modality

\begin{tabular}{|c|c|c|c|c|c|c|}
\hline \multirow{2}{*}{ Shape } & \multicolumn{3}{|c|}{ FRR } & \multicolumn{3}{|c|}{ MMO } \\
\hline & $\begin{array}{c}\text { CBCT/CT } \\
(n=16)\end{array}$ & $\begin{array}{c}\text { Panoramic } \\
\text { image }(n=14)\end{array}$ & $\begin{array}{l}\text { Periapical image } \\
\qquad(\mathrm{n}=4)\end{array}$ & $\begin{array}{c}\text { CBCT/CT } \\
(n=224)\end{array}$ & $\begin{array}{c}\text { Panoramic } \\
\text { image }(n=2)\end{array}$ & $\begin{array}{c}\text { Periapical } \\
\text { image }(n=14)\end{array}$ \\
\hline Nodule & $11(68.8)^{*}$ & $9(56.3)^{*}$ & $1(25)$ & $14(6.3)$ & $1(50)$ & $1(7.1)$ \\
\hline Ring & $9(56.3)^{*}$ & $6(37.5)^{*}$ & $3(75)$ & - & - & $4(28.6)$ \\
\hline Plate-like & $5(31.3)^{\star}$ & $3(18.8)^{\star}$ & $1(25)$ & $4(1.8)$ & - & - \\
\hline Shadow & $3(18.8)^{*}$ & $6(37.5)^{*}$ & $1(25)$ & - & - & - \\
\hline Foci & - & - & - & $216(96.4)^{*}$ & $1(50)$ & $12(85.7)$ \\
\hline
\end{tabular}

Values are presented as number (\%).

FRR, filler-related radiopacity; MMO, multiple miliary osteoma; CBCT, cone-beam computed tomography; CT, computed tomography. ${ }^{\star}$ Significant difference.
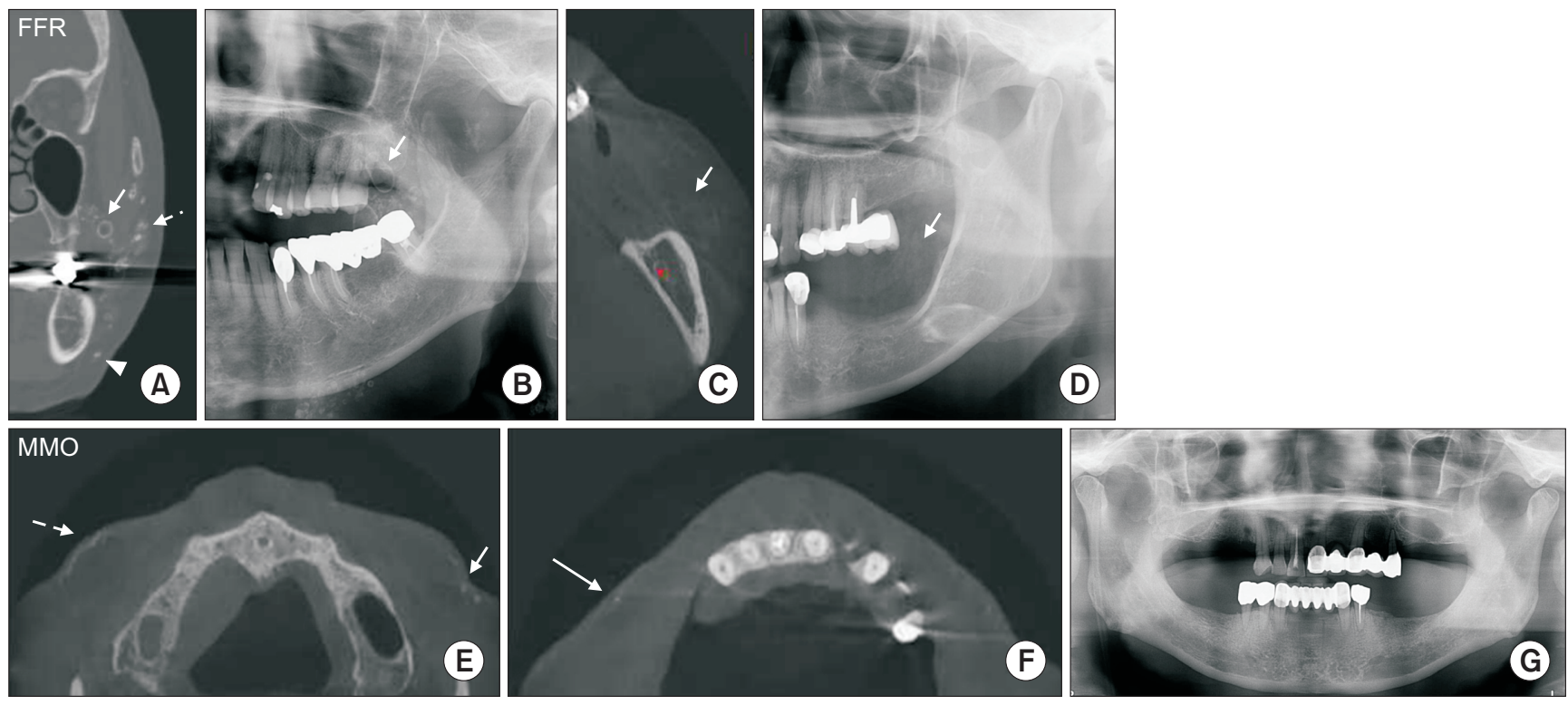

Fig. 3. Shape of FRR and MMO of 3 different cases. Case 1: CT image (A) and panoramic radiograph (B) of FRR show shapes of ring (arrow), plate (dotted arrow) and nodule (arrowhead). Case 2: CBCT image (C) and panoramic radiograph (D) of FRR reveal shape of shadow (arrow). Case 3: CBCT images (E and F) and panoramic radiograph $(\mathrm{G})$ of MMO show shapes of nodule (E, arrow), plate (E, dotted arrow) and foci (F, arrow). FRR is observed on both CT/CBCT and panoramic image whereas MMO is not detected on panoramic radiograph. FRR, filler-related radiopacity; $\mathrm{MMO}$, multiple miliary osteoma; $\mathrm{CBCT}$, cone-beam computed tomography; $\mathrm{CT}$, computed tomography.

nificantly more frequent than $\mathrm{MMO}$ in nodule, ring, platelike, and shadow shapes $(p<0.05)$, but MMO showed significantly more only foci shape than FRR $(p<0.05)$. In the panoramic image, FRR was statistically significantly higher than MMO only in nodule, ring, plate-like, and shadow shapes $(p<0.05)$. In periapical images, MMO was mostly observed as foci, without statistically significant difference. Moreover, there was no statistically significant difference regarding in all shapes between FRR and MMO, in the periapical image.
Fig. 3 showed differences in the shape and detection of FRR and MMO in three different cases of CBCT and panoramic radiograph in the same patient. Fig. 4 compared the appearance of the notable radiopacities of FRR (Fig. 4A-C) and the mild calcification of MMO (Fig. 4D, E) on intraoral radiograph. Table 4 demonstrated the comparison of detection frequencies of MMO and FRR in conventional radiographs. Most FRRs were observed in panoramic radiograph (87.5\%), however MMO was rarely detected in panoramic image $(0.9 \%)$. On periapical image, all the FRRs were well 

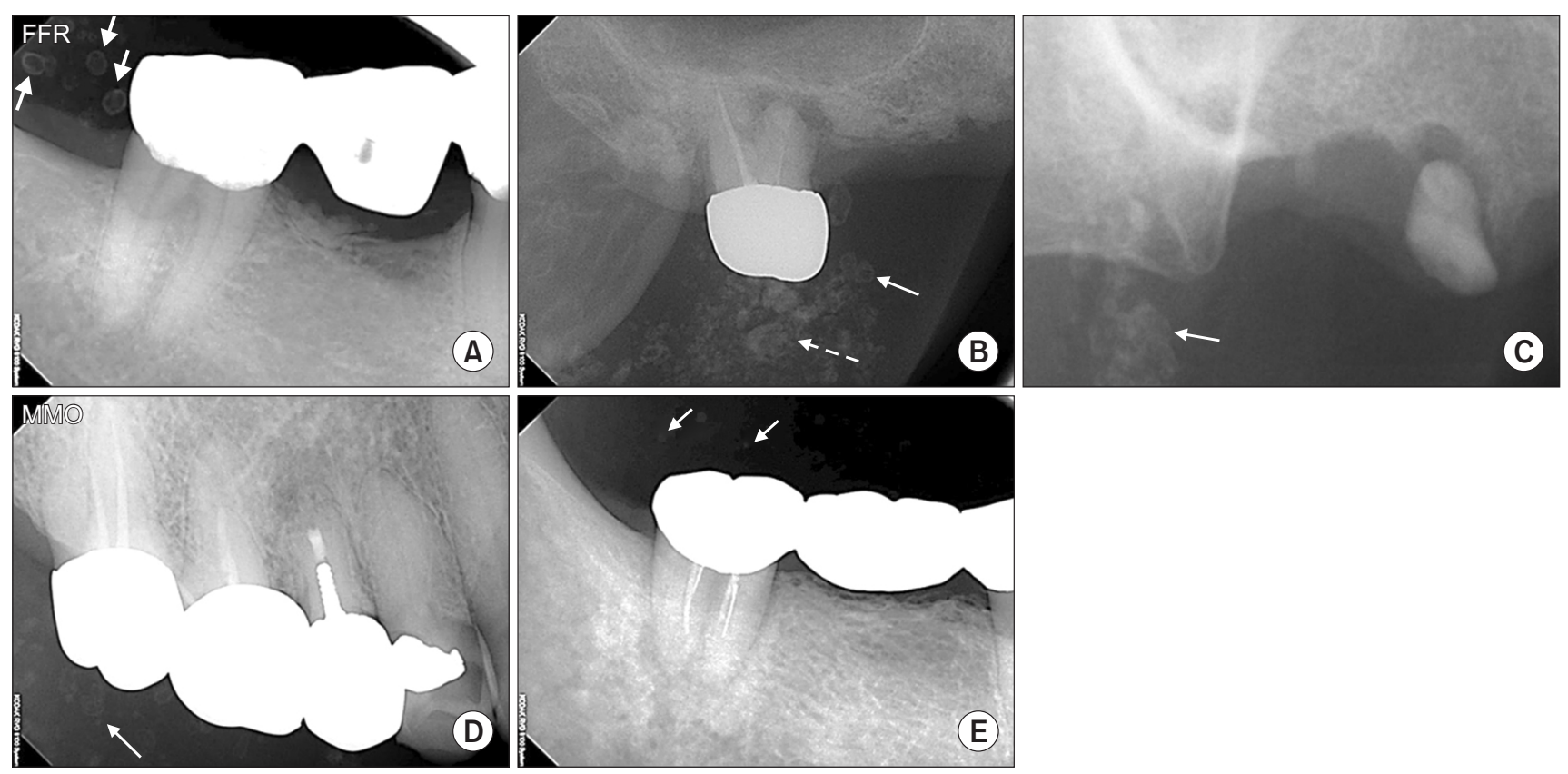

Fig. 4. Intraoral image finings of FRR and MMO. FRR shows various shapes such as ring (A, arrows), shadow (B, dotted arrow) and nodule (B, arrow), plate (C, arrow) and MMO reveals shapes of nodule (D, arrow) and foci (E, arrows). FRR, filler-related radiopacity; MMO, multiple miliary osteoma.

Table 4. Detection rate of FRR and MMO on plain images

\begin{tabular}{cccc}
\hline Plain images & FRR & MMO & $\boldsymbol{p}$-value \\
\hline Panoramic image & 14 of 16 cases $(87.5 \%)$ & 2 of 224 cases $(0.9 \%)$ & $0.000^{*}$ \\
Periapical image & 4 of 4 cases $(100 \%)$ & 14 of 23 cases $(60.8 \%)$ & 0.268 \\
\hline
\end{tabular}

FRR, filler-related radiopacity; MMO, multiple miliary osteoma. *Significant difference.

detected and MMO was more than half (60.8\%) confirmed. The $\chi^{2}$ test indicated that FRR in the panoramic image was found to be significantly better detected than MMO. In periapical image, although FRR was observed at 100\% in all periapical images, but there was no statistically significant difference in detection rate compared to MMO detection $(60.8 \%)$

\section{Discussion}

To our knowledge, the present study is an original study that compares of the radiographic findings of FRR and $\mathrm{MMO}$ on both $\mathrm{CBCT} / \mathrm{CT}$ scans and plain radiography. CT and MRI characteristics of widely used fillers are summarized on Table $5[3,16,17]$. Since CaHA has the highest radiopacity among other fillers, it is most likely to appear visible in X-ray imaging $[7,18]$. Although liquid silicone and polyacrylamide gel have not been approved by the US Food and Drug Administration (FDA) for reported adverse reactions of filler injection, they are still included in this table because they are commonly observed in imaging studies of women over 40 years of age [16].

In this study, we investigated the features of FRR observed on 2D and 3D imaging. As the demand for noninvasive cosmetic treatment grows, literatures dealing with filler characteristics and its side effects are increasing proportionately in pathology, dermatology and even in dentistry. A case report dealing with incidental findings of FRR in intraoral, panoramic, CBCT images taken for implant placement of partially edentulous patient was similar to our results [7]. According to Mupparapu and Mozaffari [5], FRR located on both cheeks can be revealed as a radiopaque 
Table 5. The image findings of soft tissue filler

\begin{tabular}{|c|c|c|c|}
\hline Filler & CT findings & MRI findings & FDA approval (yr) \\
\hline Collagen or collagen mixed with PMMA & Fluid a. & Low s. (T1), high s. (T2) & $1981(2006)$ \\
\hline e-PTFE $=$ Gore-Tex ${ }^{\mathrm{a}}$ & $\begin{array}{l}\text { Intermediate a. } \\
300-400 \mathrm{HU}\end{array}$ & Low s. (T1, T2) & Mid-1990s \\
\hline $\mathrm{HA}$ & Nearly fluid a. & Low s. (T1), high s. (T2) & 2003 \\
\hline PLLA & Soft-tissue a. & - & 2004 \\
\hline $\mathrm{CaHA}^{\mathrm{b}}$ & $\begin{array}{l}\text { Hyper a. } \\
(280-700 \mathrm{HU})\end{array}$ & Low-intermediate s. (T1, T2) & 2006 \\
\hline Liquid silicone & $\begin{array}{l}\text { Similar or slightly higher a. } \\
\text { than soft tissue }\end{array}$ & High s. (T1), iso-hypointense s. (T2) & Not approved \\
\hline PAAG & Nearly fluid a. & Low s. (T1), high s. (T2) & Not approved \\
\hline Polyacrylamide Gel (PAAG) & Nearly fluid a. & low s. (T1), high s. (T2) & not approved \\
\hline
\end{tabular}

CT, computed tomography; MRI, magnetic resonance image; FDA, US Food and Drug Administration; PMMA, poly-methylmethacrylate; ePTFE, expanded polytetrafluoroethylene; PLLA, poly-L-lactic acid; HA, hyaluronic acid; CaHA, calcium hydroxyapatite; PAAG, polyacrylamide gel; a., attenuation; s., signal; HU, hounsfield unit; FDG-PET, fluorodeoxyglucose-positron emission tomography.

${ }^{a}$ Not included in the filler category specified by FDA, but FDA approved in 1995 as "Gore-tex facial implant" category. ${ }^{b}$ FDG-PET image reveals hypermetabolic CaHA [16].

material with various shapes ranging from 3-15 $\mathrm{mm}$ in size on the intraoral or bitewing radiographs of the posterior teeth. It also can be seen in the panoramic radiograph with various forms such as donut (inner radiolucent and an outer radiopaque rim), cluster of amorphous calcification or patchy radiopaque area [5].

These discrete radiopacities can be presented in the image by the tissue response to foreign materials such as the filler or filler itself. The histological forms of foreign-body granulomas, the giant cell granuloma type and the macrophage types, are related to the material of filler used (e.g., hyaluronic acid [2], poly-L-lactic acid [2], polyacrylamide gel [19,20], poly-methylmethacrylate [21]) [3,22]. The imaging features of foreign-body granulomas are hard foci or nodule associated with irregular micro-calcified particles or small round rings or large eggshell calcifications [4]. Therefore, calcification of the large ring shape observed in the FRR case of the present study can be estimated mostly due to this reaction. Injectable silicone was introduced 40 years ago as a non-absorbable material and was widely used as a first filler to improve wrinkles [23]. However, owing to a serious side effect, US FDA has banned the use of this material for cosmetic purposes. Foreign-body granuloma has also been found to be the most abundant in off-label silicone oil $[3,23,24]$. This is because most FRR cases were subjected to unauthorized facial augmentation procedures 30-50 years ago, and the filler material is likely to be silicon which is most widely used at that time, illegally in Korea.

In fact, 2 of 16 FRRs were not visible on the panoramic image. One was localized in the nose and the other restricted in the nasolabial fold, so they could not be easily found in the panoramic image owing to its overlapping with other osseous structures and insufficient density of filler material. The findings suggest that the filler may be missed in the panoramic radiograph by blurring or escaping from the focal trough, by overlapping multiple anatomical structures, and by the similarity to the radiopacity of the surrounding tissue; besides we found that the radiopacities of filler showing from fluid to hard tissue density according to not only on the filler component, but also on the injection site $[3,16,18]$.

MMO was first described by Wilekens in 1858 and appeared to be tiny extra-skeletal bone formation that develops in the dermis and subcutaneous tissue [25]. The ossification occurs primarily in healthy skin, or secondary in neoplastic or inflammatory skin lesions that already exist [10]. The MMO of the cadaver skin observed in contact radiography was nodule, oval, or gourd-shaped with diameters ranging from 0.5 to $2.0 \mathrm{~mm}$ and distributed mainly symmetrically to the cheek, mandibular angle and forehead [26]. In a conventional occlusal radiograph, MMO is scattered amorphously in the skin, but when the X-ray beam is irradiated perpendicular to the skin, it forms a certain layer below the skin [11]. In the tangential projection radio- 
graphs taken with the air blown into the buccal cheek with cotton rolls placed in the vestibule, tiny calcifications with a well-defined margin on the skin surface were well visible [26]. Therefore, MMO can be diagnosed though imaging features without biopsy $[11,12]$.

The findings of this present study were in agreement with those of Kishi et al. [11] and Shigehara et al. [26] who found that $\mathrm{MMO}$ is mainly bilateral in both cheeks, slightly more prevalent in males, and observed more in middle ages and above. In the present study, MMO were detected almost invisible in panoramic radiographs, suggesting that MMO may be overlooked and underestimated during routine radiographic examination $[11,26]$. This is because small bone particles, such as MMO, are often not detected on panoramic image if they are superimposed on hard tissue such as a very thick facial bone or teeth or the calcification [11,26]. Exceptionally, 2 of the $224 \mathrm{MMO}$ cases were seen in the panoramic view. One MMO case was below the mandibular inferior cortex area which aligned with focal trough. The other was in the both cheek area which edentulous posterior teeth without overlaping with the teeth. In addition, MMO proved to be detected better on the periapical radiograph than on panoramic image because of its proximity to the buccal cheek [1]. This is consistent with the results of the current study, which is better seen on the periapical image $(14 / 23,60.8 \%)$ than the panoramic view (2/224, $0.9 \%)$. Therefore, rare detection of MMO may be due to the difficulty of diagnosis by routine dental radiography, not by the rarity of the condition itself [26].

Possible diagnosis for multiple facial radiopacities include calcified phlebolith, dystrophic calcification, MMO and exogeneous cosmetic material such as filler $[5,7,27]$. Phlebolith can be easily differentiated due to association with soft tissue hemangiomas [28,29]. Dystrophic calcification can be diagnosed clinically because of associated disease (e.g., panniculitis, Ehlers-Danlos syndrome etc.), infection, trauma history, keloid tissue or bump of calcified mass [27]. However, MMO and FRR are often clinically asymptomatic $[1,10,11,30-32]$ and they may be difficult to diagnose with plain images alone. Dental practitioners and oral and maxillofacial radiologists are familiar with the imaging features of FRR which differentiate from true pathology $[1,6]$ and often ask the patient about detailed history of cosmetic filler injections [7,19,23].

The retrospective design of our study led to limitations, which did not reveal the exact type of the filler. Most of the subjects who have undergone the filler treatment were women older than 50 years old with unauthorized cosmetic treatment history decades ago. This leads them to forget the name of filler material injected in the past. In addition, although there were no clinical symptoms associated with FRR in this study, there were also case reports of side effects such as buccal swelling owing to filler infection in the oral and maxillofacial surgery $[19,23]$. Therefore, in the following study, it may be necessary to study with regards to the relationship of clinical symptoms and their image characteristics.

In conclusion, FRR was mostly observed with various appearances of multiple symmetrical radiopacities in the deeper layers, whereas MMO was hardly visible in panoramic radiographs. Currently the interest in esthetics and cosmetic interventions are on the rise, oral and maxillofacial radiologists need to expand the area of diagnostic activity for multiple facial radiopacities such as FRR. When FRR is suspected, the dentist as well as the patient should actively describe the cosmetic filler history to differentiate it from pathologic condition.

\section{Acknowledgements}

This study was supported by the National Research Foundation of Korea (grant NRF-2019R1A2C101122613), funded by the Ministry of Education, Science and Technology, Republic of Korea.

\section{Conflicts of Interest}

The authors declare that they have no competing interests.

\section{ORCID}

\author{
Young-Eun Kwon \\ https://orcid.org/0000-0001-5795-6968 \\ Seo-Young An \\ https://orcid.org/0000-0001-6711-5986
}




\section{References}

1. Alsaadi G, Jacobs R, Quirynen M, van Steenberghe D. Soft tissue augmentation of the cheeks detected on intra- and extraoral radiographs: a case report. Dentomaxillofac Radiol 2008;37:117-120. doi: 10.1259/dmfr/32951026.

2. Shahrabi-Farahani S, Lerman MA, Noonan V, Kabani S, Woo SB. Granulomatous foreign body reaction to dermal cosmetic fillers with intraoral migration. Oral Surg Oral Med Oral Pathol Oral Radiol 2014;117:105-110. doi: 10.1016/j.oooo.2013.10.008.

3. Ginat DT, Schatz CJ. Imaging features of midface injectable fillers and associated complications. AJNR Am J Neuroradiol 2013;34:1488-1495. doi: 10.3174/ajnr.A3161.

4. Hirsch RJ, Stier M. Complications of soft tissue augmentation. J Drugs Dermatol 2008;7:841-845.

5. Mupparapu M, Mozaffari E. Bilateral calcifications secondary to synthetic soft tissue augmentation of the cheeks: report of a case. Dentomaxillofac Radiol 2002;31:388-390. doi: 10.1038/sj.dmfr.4600722.

6. Kemp HK. Buccal radiopacities associated with cosmetic wax implants. Br Dent J 1982;152:134. doi: 10.1038/ sj.bdj.4804766.

7. Valiyaparambil J, Rengasamy K, Mallya SM. An unusual soft tissue radiopacity--radiographic appearance of a dermal filler. Br Dent J 2009;207:211-212. doi: 10.1038/ sj.bdj.2009.764.

8. Myllylä RM, Haapasaari KM, Palatsi R, Germain-Lee EL, Hägg PM, Ignatius J, Tuukkanen J. Multiple miliary osteoma cutis is a distinct disease entity: four case reports and review of the literature. Br J Dermatol 2011;164:544-552. doi: 10.1111/j.1365-2133.2010.10121.x.

9. Chabra IS, Obagi S. Evaluation and management of multiple miliary osteoma cutis: case series of 11 patients and literature review. Dermatol Surg 2014;40:66-68. doi: 10.1111/dsu.12389.

10. Thielen AM, Stucki L, Braun RP, Masouyé I, Germanier L, Harms M, Salomon D, Borradori L. Multiple cutaneous osteomas of the face associated with chronic inflammatory acne. J Eur Acad Dermatol Venereol 2006;20:321-326. doi: 10.1111/j.1468-3083.2006.01425.x.

11. Kishi K, Kawahara K, Moriya I, Komatsu H, Sato M, Aono K. Clinical and radiographic study of multiple miliary osteomas of the skin. Dentomaxillofac Radiol 1984;13:105-108. doi: 10.1259/dmfr.1984.0011.

12. Safi Y, Valizadeh S, Vasegh S, Aghdasi MM, Shamloo N, Azizi Z. Prevalence of osteoma cutis in the maxillofacial region and classification of its radiographic pattern in cone beam CT. Dermatol Online J 2016;22:13030/qt1x769989. doi: $10.5070 / D 3221029781$.

13. Liang X, Jacobs R, Hassan B, Li L, Pauwels R, Corpas L, Souza PC, Martens W, Shahbazian M, Alonso A, Lambrichts
I. A comparative evaluation of Cone Beam Computed Tomography (CBCT) and Multi-Slice CT (MSCT) Part I. On subjective image quality. Eur J Radiol 2010;75:265-269. doi: 10.1016/j.ejrad.2009.03.042.

14. Cha JY, Mah J, Sinclair P. Incidental findings in the maxillofacial area with 3-dimensional cone-beam imaging. Am J Orthod Dentofacial Orthop 2007;132:7-14. doi: 10.1016/ j.ajodo.2005.08.041.

15. Bouraoui S, Mlika M, Kort R, Cherif F, Lahmar A, Sabeh M. Miliary osteoma cutis of the face. J Dermatol Case Rep 2011;5:77-81. doi: 10.3315/jdcr.2011.1082.

16. Feeney JN, Fox JJ, Akhurst T. Radiological impact of the use of calcium hydroxylapatite dermal fillers. Clin Radiol 2009;64:897-902. doi: 10.1016/j.crad.2009.05.004.

17. Chacon AH. Fillers in dermatology: from past to present. Cutis 2015;96:E17-E19.

18. Carruthers A, Liebeskind M, Carruthers J, Forster BB. Radiographic and computed tomographic studies of calcium hydroxylapatite for treatment of HIV-associated facial lipoatrophy and correction of nasolabial folds. Dermatol Surg 2008;34 Suppl 1:S78-S84. doi: 10.1111/j.15244725.2008.34247.x.

19. Karagozoglu KH, van der Waal I. Polyacrylamide soft tissue filler nodule mimicking a mucoepidermoid carcinoma. Int J Oral Maxillofac Surg 2008;37:578-580. doi: 10.1016/ j.ijom.2008.01.008.

20. Kawamura JY, Domaneschi C, Migliari DA, Sousa SO. Foreign body reaction due to skin filler: a case report. Oral Surg Oral Med Oral Pathol Oral Radiol Endod 2006;101:469-471. doi: 10.1016/j.tripleo.2005.04.022.

21. Quirino MR, Neves AC, Campos MS, Brandão AA, Anbinder AL. Oral granuloma formation after injection of cosmetic filler. J Craniomaxillofac Surg 2012;40:e194-e197. doi: 10.1016/j.jcms.2011.10.007.

22. Lombardi T, Samson J, Plantier F, Husson C, Küffer R. Orofacial granulomas after injection of cosmetic fillers. Histopathologic and clinical study of 11 cases. J Oral Pathol Med 2004;33:115-120. doi: 10.1111/j.1600-0714.2004.00194.x.

23. Mandel L, Addison S, Clark M. Buccal reaction to silicone cosmetic filler. J Am Dent Assoc 2010;141:162-166. doi: 10.14219/jada.archive.2010.0134.

24. Kontis TC, Rivkin A. The history of injectable facial fillers. Facial Plast Surg 2009;25:67-72. doi: 10.1055/s-0029-1220645.

25. Essing M. [Osteoma cutis of the forehead]. HNO 1985;33: 548-550. German.

26. Shigehara H, Honda Y, Kishi K, Sugimoto T. Radiographic and morphologic studies of multiple miliary osteomas of cadaver skin. Oral Surg Oral Med Oral Pathol Oral Radiol Endod 1998;86:121-125. doi: 10.1016/s1079-2104(98) 90161-5.

27. Walsh JS, Fairley JA. Calcifying disorders of the skin. J Am Acad Dermatol 1995;33(5 Pt 1):693-706; quiz 707-710. doi: 10.1016/0190-9622(95)91803-5. 
28. Smith JF, Drake J, Sollee N. Massive oral hemangioma with phlebolithiasis. Oral Surg Oral Med Oral Pathol 1966;21:83-88. doi: 10.1016/0030-4220(66)90018-1.

29. Ikegami N, Nishijima K. Hemangioma of the buccal pad with phlebolithiasis: report of a case. Acta Med Okayama 1984;38:79-87. doi: 10.18926/AMO/30364.

30. Aguinaga F, Trope B, Piñeiro-Maceira J, Ramos-E-Silva M.
Miliary osteoma cutis: a case report. Case Rep Dermatol Med 2014;2014:347829. doi: 10.1155/2014/347829.

31. Goldminz D, Greenberg RD. Multiple miliary osteoma cutis. J Am Acad Dermatol 1991;24(5 Pt 2):878-881. doi: 10.1016/0190-9622(91)70138-r.

32. Bowman PH, Lesher JL Jr. Primary multiple miliary osteoma cutis and exogenous ochronosis. Cutis 2001;68:103-106. 